\title{
NUEVOS TESTIMONIOS DE ASPIRACIÓN DE /S/ IMPLOSIVA EN LOS ALBORES Y FINALES DEL SIGLO XVII GRANADINO
}

\author{
José M. ${ }^{a}$ Chamorro Martínez \\ Universidad de Granada
}

A lo largo de nuestra historia literaria no han faltado alusiones a la peculiaridad lingüística de los andaluces respecto de la natural de los castellano-hablantes ${ }^{1}$. Hacia finales del XIV ya hay referencias manifiestas gracias a los datos aportados por el converso aragonés Gonzalo García de Santa María, quien escribe las siguientes palabras:

Ay allende esso en la misma Castilla, como son diuersos reynos en vno ayuntados, algunas tan grosseras y ásperas lenguas como es Galizia, Vizcaya, Asturias y Tierra de Campos, que ni aquellas ni lo muy andaluz es auido por lenguaje esmerado. $\mathrm{Ca}$ lo vno de muy gruesso y rudo se pierde, y lo otro de muy morisco en muchos vocablos a penas entre los mismos castellanos se entiende [...]. Y luego que el mote o palabra es de muy andaluz tan çerrada, que a malaués en el mismo Reyno, saluo en aquel lugar solo donde le hablan, se entiende ${ }^{2}$.

Como se puede observar, las referencias respecto del modo de hablar de los andaluces se centran fundamentalmente en la diversidad que parece presentar su campo léxico, pero si bien se mira ¿qué encierra la expresión de Gonzalo García de Santa María cuando afirma que lo «muy andaluz» no es tenido por «lenguaje esmerado»? Hasta el momento todo son conjeturas

\footnotetext{
${ }^{\prime}$ Sobre esta cuestión trata ampliamente J. A. Frago Gracia en «El andalucismo lingüístico en textos eruditos y literarios», en Historia de las hablas andaluzas, Madrid, Arco/Libros, 1993, págs. 103-208. Asimismo véase el excelente y documentado trabajo de F. González Ollé, «Primeras noticias y valoraciones del andaluz», BRAE, LXVII, 1987, págs. 347-387.

${ }_{2}^{2}$ Las vidas de los sanctos padres religiosos et sus castigos y enxemplos que dieron contra los vicios et peligros deste mundo, trasladadas por sant Hierónymo et agora de nueuo reconocidas et hystoriadas, Valencia, en casa de Juan Jofré, 1529, f. 2r. El texto lo tomo del capítulo citado en la nota 1 , especialmente las págs. 106-107.
} 
acerca del enigma que ocultan tales palabras, aunque a mi parecer, y en esto coincido con Frago, no es el léxico lo que llama su atención, sino la particularidad que presentan muchos andaluces a la hora de articular algunos rasgos fónicos del sistema fonológico castellano.

Conjeturando aún más, cabría preguntar si tal vez entre lo realmente extraño y espurio a los oídos de gran parte de la comunidad castellano-hablante no podría incluirse, entre otros cambios, el modo harto diferente de articular la /s/ hasta el punto de que los gramáticos no estimaran pertinente dar testimonio de tan deturpada articulación y, por ello, digna, de ser reprobada aunque estuviera difundida entre el vulgo.

A los testimonios literarios aducidos por Frago he de añadir otro del siglo XVII que continúa dándonos pistas de las peculiaridades articulatorias de los andaluces, aunque sin detenerse a precisarlas:

Quiso él agradecérmelo, mas apenas su voz llegó a mis oýdos, [...], hizo patente su sonido $\mathrm{y}^{\prime}$ pronunciación, conociendo con evidencia clara que quien tenía delante era don Francisco de Silva, el que en Sevilla me dexó y se fue con Rufina y, en fin, el mayor amigo y compañero de mis mocedades y locuras ${ }^{3}$.

En el texto, en el que no se da relación de característica articulatoria alguna, sí se precisa en cambio que es «su sonido y pronunciación» lo que lo delata como andaluz. Considerando que se alude a una persona natural de Sevilla, lo que tal vez le ayudó a reconocerlo fuera, además de la tonalidad de sus habitantes, el seseo propio de la capital, la aspiración procedente /f-/ y el yeísmo, si nos atenemos a lo tradicionalmente considerado como rasgos del habla sevillana de antaño. Pero quien así distingue al sevillano, precisa otros rasgos físicos, además del lenguaje, para destacar a un miembro de la raza gitana: el talle y el color.

Baxé, y con mi presencia se sossegaron y assistieron a las demandas y respuestas que tuve con el preso, que a esta hora, assí en el talle como en el lenguaje y color, no me pudo negar el ser gitano ${ }^{4}$.

Además de las modificaciones lingüísticas, otros rasgos externos permiten conocer a los nativos de otras regiones: el peculiar modo de vestir y sus costumbres.

Mi dueño era andaluz y ella de Estremadura, diferentes en tierras, en trages y costumbres ${ }^{5}$.

\footnotetext{
${ }^{3}$ Gonzalo de Céspedes y Meneses, Varia fortuna del soldado Píndaro, edición, prólogo y notas de Arsenio Pacheco, Madrid, Clásicos Castellanos, 1975, II, pág. 79, lín. 22 y ss.

${ }^{4}$ Ibidem, pág. 75 , lín. 26 y ss.

5 Ibidem, pág. 73 , líns. 13-15.
} 
Manuel Ariza da una breve pero excelente exposición cronológica de la aspiración de $s$ implosiva abordando los distintos puntos de vista de los que han tratado esta cuestión ${ }^{6}$, y cuyo criterio, coincidente con los que defienden su tardía manifestación, expone del siguiente modo:

¿Cómo estar seguros de cuál de las dos interpretaciones es cierta? Porque los defensores de la cronología temprana aducen que las aspiraciones se dan también en zonas de la Meseta, incluso en Madrid, lo que -en su opinión - indica que la aspiración y pérdida fue muy antigua y muy general. Sin embargo no me creo que la aspiración madrileña - pongo por casosea genuina, sino producto de la emigración de extremeños y andaluces; por otra parte, si los ejemplos gráficos de pérdida son reales, ¿cómo explicar ejemplos -andaluces del siglo $\mathrm{xV}$ - como el dicho exámenes? ${ }^{7}$.

Ante su toma de posición respecto del momento en que tiene lugar la aspiración madrileña es necesario precisar que la emigración a que se refiere el autor comienza aproximadamente hacia los años cuarenta de este siglo $\mathrm{xx}$, como resultado de la indigencia en que se vio sumida España a causa de la guerra civil. Ahora bien, no se trata sólo de la aspiración observada en la gran metrópoli, sino también de la existente en el occidente santanderino ${ }^{8}$ y Castilla la Nueva ${ }^{9}$, entre otras zonas, en donde la emigración no pudo influir gran cosa en tan corto espacio de tiempo. De cualquier modo hay que advertir que los cambios fónicos a los que aluden los defensores de la aspiración temprana de -s no son precisamente los acaecidos en nuestro siglo, sino muy anteriores, y es de éstos de los que se debe dar una explicación convincente.

En primer lugar hay que advertir que es sobremanera extraña la nómina de voces que determinados literatos del XVII escriben con $h$, sin ser originarios de Andalucía. Por ejemplo, Gonzalo de Céspedes, madrileño de nación, presenta las vacilaciones hoý, hoýamos, hoýdos, hoýdo junto a oýros, oí, avéis oýdo.

Presto salí de dudas y vi lo que nunca creyera, hoý, lo que ni ahora escrivo sin muy grande vergüença ${ }^{10}$.

\footnotetext{
${ }^{6}$ Véase al respecto su artículo «Reflexiones sobre la evolución del sistema consonántico en los Siglos de Oro», Actas del III Congreso Internacional de Historia de la Lengua Española (Salamanca, 22-27 de noviembre de 1993), Editadas por A. Alonso González et alii, Madrid, Arco Libros, 1996, I, págs. 43-79, especialmente págs. 48-52.

${ }^{7}$ Ibidem, pág. 50.

${ }^{8}$ Cf. M. ${ }^{\mathrm{a}}$ del Pilar Nuño Álvarez, "Cantabria», en Manuel Alvar (director), Manual de dialectología hispánica. El Español de España, Barcelona, Editorial Ariel, 1996, pág. 188.

9 Véase Francisco Moreno Fernández, "Castilla la Nueva», en Manuel Alvar, Manual de dialectologia hispánica, pág. 217.

${ }^{10}$ Varia fortuna del soldado Píndaro, II, pág. 15, lín. 2.
} 
llenando el viento de cortesías superfluas, y de furor y rabia a quantos las hoýamos ${ }^{11}$.

yo confieso que asta el presente casso, aunque diversas vezes muchos de aqueste género tenía hoýdos y vistos en muy graves autores, $[\ldots]^{12}$.

y para que imitando exemplos tan illustres como el que avéis hoýdo se anime a merecer otra igual recompensa ${ }^{13}$.

Mas el problema se acrecienta al hallar también en su obra lo siguiente: $-s f->-f f$-, empleo de $g$ por $j$ ante las vocales $a$, $o$ y no precisamente en una fugaz ocasión, así como la adición de $h$ al sustantivo umbrales cuando va precedido del artículo plural:

no era el sitio ni el tiempo convenientes para escuchar lástimas dilatadas, ni aun para defferrarle, según lo pretendí ${ }^{14}$.

Pues ¿qué me afligo y lloro? ${ }^{15}$

No os afligáis amigo ${ }^{16}$.

Y oyendo que afirmaba avérsele perdido, creciendo la sospecha, mandó descerragarle [el aposento] ${ }^{17}$.

intrépido [el animal] se abalançó al çaguán, atropellándole y dexando a mi camarada tendido en los humbrales medio muerto ${ }^{18}$.

No cabe pensar, pues, en errores fortuitos por quebrantamiento accidental de la norma lingüística, sino en algo más profundo que debió ocurrir en la sociedad y que una reacción posterior enderezó, al menos parcialmente. De ahí que no extrañe encontrar quien considerando que fenómenos no tenidos por habituales en Castilla, y hoy son moneda corriente, sostenga que la razón

11 Ibidem, II, pág. 98, lín. 5; pero «en lo que avéys oýdo», pág. 117, lín. 21.

12 Ibidem, I, pág. 169, lín. 1. En la 170, lín. 5, volvemos a encontrar «ofrecíamos silencio, mejoramos asientos y abríamos los hoýdos». En cambio, lo vemos $\sin h$ en las siguientes págs.: 175, lín. 7: «pues aunque hemos de oýros»; pág. 182, lín. 21: «y aun agravado de aquellos pensamientos, oí, no sin [...]»; pág. 196, lín. 28: «quanto ya avéis oýdo».

${ }^{13}$ Ibidem, I, pág. 203, lín. 35 . Y en la 206: «revelando la esclava, archivo desta historia, a su afligido padre quanto ya avéis hoýdo».

${ }^{14}$ Ibidem, II, pág. 155, lín. 26. En la pág. 156, lín. 20, el autor, en cambio, escribe desherrado: «hasta estás desherrado».

${ }^{15}$ Ibidem, I, pág. 74, lín. 23. El editor advierte en la nota 23 que corrige el original afligo por aflijo.

${ }_{16}$ Ibidem, II, pág. 107, lín. 1. El editor lo corrige por aflijáis.

17 Ibidem, I, pág. 184, lín. 28

18 Ibidem, I, pág. 164, lín. 33. 
de su existencia no es más que producto de un influjo emigratorio de personas en cuyo bagaje articulatorio no escaseaban ésos y otros muchos cambios.

Lo afirmado podría quedar en agua de borrajas, si no lloviera sobre mojado. Y mojado es hallar que otro escritor coetáneo, y también madrileño por más señas, presente aspiraciones en las que «teóricamente» no debiera haber incurrido por no ser, según se dice, fenómeno propio del lugar. Me refiero a Juan Cortés de Tolosa, quien pone en boca de un criado la siguiente descripción:

[mi ama] era blanca, ni muy flaca ni muy gruessa, tenía lindas figuras y hermosíssimas manos, lindos hojos, gran donayre y, finalmente, era muy dama y toda ella rebuena ${ }^{19}$.

Esto es, el mismo cambio que el hallado en la obra de Gaspar Fernández y Ávila ${ }^{20}$ : mis jorejas, dambos jojos, unos jojos, etc., aunque en Cortés de Tolosa se halle con $h$.

Mas tampoco es un dato aislado, pues, como Céspedes, también registra humbrales:

Quándo no adoré tus humbrales ${ }^{21}$.

Esto dixo puestos los pies en los humbrales de la puerta de la ciudad ${ }^{22}$.

El fenómeno, le precediera o no $-s$, estaba tan extendido y arraigado que incluso se documenta en territorio dominicano a principios del siglo XVI (1509):

$\mathrm{q}$ [e]l dicho françisco de solis mando al dho gaspar q le atase las manos altas con vn hico al humbral alto de la puert. ${ }^{23}$.

Junto a humbrales Cortés de Tolosa emplea el correcto umbral así como la variante lumbral, con adición en este caso de la geminada lateral del ar-

\footnotetext{
19 Juan Cortés de Tolosa, Lazarillo de Manzanares con otras cinco novelas, Edición, introducción y notas de Giuseppe E. Sansone, Madrid, Clásicos Castellanos, 1974, I, pág. 23, lín. 13.

${ }^{20}$ Cfr. La Infancia de Jesu-Christo. Poema dramático dividido en doce coloquios. Estudio, edición crítica, notas y vocabulario por Francisco Torres Montes, Universidad de Granada, 1987, pág. 34.

${ }^{21}$ Ibidem, I, pág. 78 , lín. 10.

${ }^{22}$ Ibidem, II, pág. 70, lín. 6.

${ }^{23} \mathrm{M}^{\text {a }}$ Beatriz Fontanella de Weinberg (compilación), Documentos para la historia lingüística de Hispanoamérica. Siglos XVI a XVIII. Asociación de Lingüística y Filología de América Latina. Comisión de estudio histórica del español de América, Madrid, Anejo LIII del Boletín de la Real Academia, Madrid, 1993, I, Santo Domingo, año 1509, pág. 10, lín 7.
} 
tículo al sustantivo y conocido rasgo vulgar dentro del ámbito que solemos llamar español meridional.

Dexé, pues, caer en el suelo mis vestidos, y tomándolos uno dellos, los puso en el lumbral de una puerta ${ }^{24}$.

Aunque no es el único ejemplo de asimilación por cuanto en otro lugar pone en boca de un matachín la siguiente imprecación:

Levántese vuessa merced, que no tiene nada, que con el dedo le dio mi hermano, y no cuyde de açotar a nadie. Particularmente a andaluzes, porque, $i$ voto allijo! que no ay ningún estudiante de quantos vuessa merced ve cada día que no vaya hecho un estuche ${ }^{25}$.

Aún más, en documentos castellanos tampoco faltan ejemplos de $-s$ final de sílaba elidida: obipo 'obispo', arçobipado, obipado, que por su profusión en el manuscrito no creo que se deba a mero descuido del escriba.

e que es contador del obipo de Cuenca, e que tratta mercadería de pannos ${ }^{26}$.

que sean resçebidos en cuenta al arrendador, o arrendadores del arçobipado, o obipado, o mirindad, o sacada, $[\ldots]^{27}$.

Alonso Lópes del Alverca, escúsase por alguasil del obipo e por su casero ${ }^{28}$.

He sostenido en otro lugar ${ }^{29}$ que la sustitución de $-s$ por $h$ debió ser muy antigua porque, de no ser así, no se comprende que en el siglo XVI haya tal abundancia de voces con $h$ tanto en España como en los nuevos territorios conquistados, y cuya generalización llega hasta el punto de hallarla incluso en voces en las que no ha lugar: herales 'erales', hasna 'asna', hellos 'ellos', holvidan 'olvidan', hasarla 'asarla', háspera 'áspera', heditos 'edictos', etc.

Utreras, como vacas vaçías. Como herales a quinientos. Añojos a trezientos. Yeguas paridas a mill quinientos ${ }^{30}$.

\footnotetext{
${ }^{24}$ Ibidem, I, pág. 93, lín. 4.

25 Juan Cortés de Tolosa, Lazarillo de Manzanares..., I, pág. 98, lín. 31. En la nota 31 advierte el editor: «La expresión encuentra una comprobación en el cervantino allombre. Cfr. Fontecha, ob. cit.: allombre».

${ }^{26}$ A. Romero Martínez, El sistema fiscal en la corona de Castilla: Formas de recaudación $y$ génesis documental. Tesis doctoral inédita defendida en la Facultad de Filosofia y Letras de la Universidad de Granada en 1994, doc. 36, a. 1451, Madrid, pág. 1428, lín 1, copia coetánea.

${ }^{27}$ Ibidem, doc. 36, a. [1458], pág. 916, n. ${ }^{\circ}$ [12], copia coetánea. Documentos reales.

${ }^{28}$ Ibidem, doc. 6, a. 1454, Chinchilla, pág. 1553, n. ${ }^{\circ}$ [516], doc. original. Padrones.

${ }^{29}$ "Consideraciones historico-críticas sobre fonética andaluza», (en prensa).

30 A. Romero Martínez, El sistema fiscal,,,, doc. 54, a. 1500 [Sevilla], pág. 1240, lín. 24. Traslado realizado en Sevilla en 1538.
} 
Ruy Ximénes es su contía, en heredades e una hasna e un telar, quatro mill e treçientos maravedís ${ }^{31}$.

e derechamente empadronaría la dicha colaçión e vezinos e moradores della syn yncubrir alguno dellos e que en los apreçios dellos hellos dirían lo que supiesen ${ }^{32}$.

Por ende, verás lyndas mugeres con viles, feos e desaventurados honbres, e para poco, e pobres, se enbolver, asý coxos como mancos e tuertos, e los gibados non los holvidan ${ }^{33}$.

Los ha bisto muchas vezes que los dichos yndios comen carne umana e aun no aguardan muchas vezes a hasarla ni coçella ${ }^{34}$.

y estar las casas de los yndios muy apartadas una de otra y ser aquella tierra la más háspera y de mayores sierras que ay en las Yndias ${ }^{35}$.

$\mathrm{y}$ sobre todo lo dicho ha fecho e haze juntas y sínodos $\mathrm{y}$ ha hecho leer muchos heditos públicos en las Yglesias ${ }^{36}$.

Nuevos datos me hacen sustentar el planteamiento de los que estiman que el fenómeno no pudo darse en época tan tardía; y lo hago de forma tan concluyente por haber hallado ejemplos anteriores al XVIII, sobre los que no cabe el recurso de la duda. El primero de ellos, acaecido en posición interior de palabra, se halla en un manuscrito cuya transcripción he llevado a cabo minuciosamente; mientras que el segundo, originado por fonética sintáctica, lo encuentro en una transcripción ya elaborada cuyo original he podido consultar. De ambos adjunto fotocopia al final del trabajo.

A tenor de dichos registros será preciso adelantar la fecha del cambio fonológico casi dos siglos por pertenecer el primer documento a la segunda mitad del XVII, mientras el segundo corresponde a la primera década de dicho siglo.

El de menor antigüedad, el que ofrece la aspiración de $-s$ interior de palabra, se halla en un folio manuscrito de 1675 en donde el escribano, que

${ }^{31}$ Ibidem, doc. 9, a. 1485, Jaén, pág. 1669, n..$^{\circ}$ [043]. Traslado realizado en Granada en 1566 por el escribano Pedro de la Torre.

32 Ibidem, doc. 9, a. 1485, Jaén, pág. 1663, lín. 21. Traslado llevado a efecto en Granada en 1566 por el escribano citado en la nota anterior.

${ }^{33}$ Alfonso Martínez de Toledo, Arcipreste de Talavera o Corbacho, Edición, introducción y notas de J. González Muela, Madrid, Clásicos Castalia, 1970, cap. XVIII, pág. 81. Edición hecha sobre la de Toledo de 1500 .

${ }^{34}$ Sara Rodicio García, «Las probanzas de don Juan Valle, protector de indios», Estudis Castellonencs, n. ${ }^{\circ} 6,1994-1995$, t. II, págs. 1157-1165, especialmente pág. 1162, § III. Mediados del Xvi.

${ }^{35}$ Ibidem, II, pág. 1161, § II.

36 Ibidem, II, pág. 1164, § IV. 
anota y da fe del hierro y de la señal con que una persona desea marcar su ganado, escribe en un primer momento lo que sigue:

Jierro y señal que en su ganado vacuno y demás hechaua Juan de Santiago, vezino de Sagra y, por su muerte, el día doçe de febrero de mill seisçientos y setenta y cinco lo rexistró, éste que está ehtanpado, Francisco de Santiago, su ijo [...] ${ }^{37}$.

Percatado de su error, el escribano enmienda ehtanpado trazando una $s$ sobre el rasgo alargado de $h$, aunque deja sin tachar la curvatura superior e inferior de la misma, circunstancia afortunada que nos permite poder hablar sin ambages, primero, de la realidad de la aspiración de $-s$ en una época en que salvo unos pocos nadie creía posible; y, segundo, que de modo inconsciente, el escribano ha dejado constancia de la peculiaridad articulatoria de que disfrutaría la comunidad lojeña, y que como tal hábito social ha llegado hasta nuestros días.

Del inusual hallazgo pueden dar fe las siguientes palabras de don Ramón:

Esta aspiración de las sibilantes en posición final de sílaba es difícilmente documentable a través de la escritura; en consecuencia carecemos de claros testimonios antiguos ${ }^{38}$.

El afortunado descubrimiento del insólito ehtanpado y demás registros arriba citados me permite reputar como probable la existencia a comienzos del XVI de la tan traída y llevada Sofonifa 'Sophonisba' de Fernando Colón.

En el manuscrito lojeño advierto también elisión de $-s$ en regitro 'registro' y regitrado, la supresión de la $z$ de yzquierda, así como horeja, entre otros fenómenos:

para lo qual a cada uno que haga su regitro ${ }^{39}$.

de perdidos los ganados que se aprehendiese con hierros contraseñalados de otros que no deban usar y tenga regitrado cada uno ${ }^{40}$.

Hierro y señal que echa a su ganado Diego de Balenzuela, vezino de esta çiudad. En la orexa derecha vna horquilla y en la yquierda dos moscas por delante ${ }^{41}$.

${ }^{37}$ Libro de hierros y señales de ganado de esta ciudad de Loxa, Archivo Municipal de Loja, 235, fol. 295v, a. 1675, lín. 5.

${ }_{38}$ R. Menéndez Pidal, «Sevilla frente a Madrid», Estructuralismo e Historia, III, Miscelánea Homenaje a André Martinet, La Laguna, 1962, págs. 99-165. La cita en la pág. 136.

${ }^{39}$ Libro de hierros y señales...., fol. III r., a. 1679, lín. 16. Escribano, Pedro del Campo Ferreira.

${ }^{40}$ Ibidem, fol. IIv., a. 1679, lín. 6.

${ }^{41}$ Ibidem, fol. 168r., s.a. 
Hierro y señal de Juan de Porras Luque. Esta señal: la horexa derecha hendida y vn golpe por delante, y la izquierda vna mosca por detrás ${ }^{42}$.

Pero la importancia del hallazgo radica, además, en el hecho de ser el dato de mayor antigüedad en que el grafema $-s$ se manifiesta reproducido por $h$; $y$ digo de mayor antigüedad, porque en otro trabajo he dado cuenta de su existencia al hallar abreviado el sintagma que es como $q h$ en un texto también granadino de principios del XVIII ${ }^{43}$.

No cabe duda de que sin los testimonios aportados por estos escribanos tal vez continuaríamos intentando resolver el problema del origen de la aspiración de $-s$. Felizmente, el instintivo dato suministrado por los escribanos ha permitido subsanar un asunto controvertido de nuestra historia lingüística.

De todo ello infiero que los escribanos, en general, intentan escribir ateniéndose a la norma escrituraria considerada por ellos como correcta $\mathrm{y}$, por ende, evitan incurrir en errores como el descrito en estanpado; buena prueba de ello es la rectificación aducida. Sin embargo, no todos los amanuenses se percatan de sus errores grafemáticos tal y como se observa en los siguientes registros: aprejendan, dehar, héneros, rehistros, Hinez, harros 'jarros', etc.

y que los guardas del campo y ministros desta çiudad, aunque aprejendan ganados de otras jurisdiçiones $[\ldots]^{44}$.

y que no saldrán della [de la cárcel] sin primero dehar hecho dicho regitro $(\text { sic })^{45}$.

Y que asimismo todos los dichos vecinos de esta jurisdiçión que comprasen $o$ trujesen ganados de qualesquier héneros que sean $[\ldots]^{46}$.

haga libro nuevo donde señale, dibuje y asiente los dichos rehistros, hierros y señales ${ }^{47}$.

Hinez Hernando ${ }^{48}$

harros de tres cuartillos, Harros blancos de hechura de plata. Harros blancos bañados de los redondos. Harros verdes de un açumbre, quatro maravedis 49

\footnotetext{
${ }^{42}$ Libro de hierros y señales..., fol. $184 \mathrm{v}^{\circ}$, s. a.

${ }^{43}$ Hablo de ello en "Consideraciones histórico-críticas sobre fonética andaluza», ya citado en la nota 28

${ }_{44}$ Libro de hierros y señales..., fol. IIr., a. 1679.

45 Ibidem, fol. IIv, a. 1679, lín. 20.

46 Ibidem, fol. IIIr., a .1679, lín. 7.

47 Ibidem, a. 1679, lín. 13.

48 Rafael López Guzmán, Tradición y clasicismo en la Granada del siglo XVI, Granada, Diputación Provincial, 1987, doc. 1, a. 1579, El Pardo, pág. 721. Copia de 1580.

49 "Ordenanzas de los olleros», en Ordenanzas de Granada, tít. 93, fol. 202, tomado de M. ${ }^{a}$ Carmen Querol Martínez, Léxico de la alfarería granadina, Universidad de Granada, pág. 191, s.v. jarro.
} 
En los ejemplos aducidos con $h$ etimológica latina -aprehender, reprehender, etc.- ésta aparece con articulación aspirada o velar, aunque se siga afirmando que no procede tal articulación por haberla perdido la lengua latina; su pervivencia en el lenguaje popular y culto demuestra que tal vez dicho aserto no llegó a generalizarse, según se ve en los siguientes versos:

Allega los virtuosos,/ quita daños de entre nos, / estraña los maliciosos,/ reprehende los viciosos, / ama los que aman a Dios; ${ }^{50}$.

La anciana antigüedad, que comprehendes, / te aguarda, amigo Caro, en lo que escribes ; / y entre sus alabanzas, hoy recibes / la vida que a tu patria dar pretendes. ${ }^{51}$.

Como no fuí maldiziente/ en mi vida, ni lo soy, / sepan, señoras, que estoy/ sentido de alguna gente, / que, muertos por estorbar/ el coloquio, reprehenden, / también porque no le entienden/ o por gana de hablar./ ${ }^{52}$.

Con ser valioso el registro de ehtanpado, no lo son menos los hallados en la Historia eclesiástica de Granada ${ }^{53}$. En dicha obra, escrita con motivo del descubrimiento de los libros plúmbeos del Sacromonte y terminada entre junio y noviembre de 1610, el amanuense, que escribe tal vez al dictado, nos deja constancia de una peculiaridad lingüística de la sociedad granadina de la época que llega hasta nuestros días: la generalizada aspiración de -s: hornamentos, horación, herrores, etc.

se desnudava los hornamentos pontificales y reposava [98r.] sobre un estrado hasta una hora ${ }^{54}$.

Dávale pena notable al sancto arçobispo que en la cassa de horación, a los ojos de Dios, se le perdiesse la vergüença ${ }^{55}$.

Supo nuestro prelado cómo avía predicado un ministro de los hereges y enseñado muchos herrores de los que tiene Calvino en el libro de sus instituciones ${ }^{56}$.

${ }^{50}$ Diego de San Pedro, Tractado de amores de Arnalte e Lucenda, en Obras, cuarta edición. Edición, prólogo y notas de Samuel Gili Gaya, Madrid, Clásicos Castellanos, 1976, pág. 12 , vv. 30-34.

${ }_{51}$ Pedro Espinosa, Poesías completas. Edición, prólogo y notas de Francisco López Estrada, Madrid, Clásicos Castellanos, 1975, n. ${ }^{\circ} 79$, pág. 196, vv. 5-8.

52 Juan Fernández de Heredia, Obras, segunda edición. Edición, prólogo y notas de Rafael Ferreres, Madrid, Clásicos Castellanos, 1975, pág. 160, vv. 747- 754.

${ }^{53}$ Justino Antolínez de Burgos, Historia eclesiástica de Granada. Introducción, edición, notas e índices por Manuel Sotomayor, Granada, Servicio de Publicaciones de la Universidad, 1996, pág. XXXV. Mi agradecimiento al profesor Manuel Sotomayor por su diligencia en proporcionarme fotocopia del folio original del texto.

${ }_{55}^{54}$ Ibidem, pág. 170, lín 24.

55 Ibidem, pág. 182, lín. 32.

${ }^{56}$ Ibidem, pág. 249, lín. 11. En la pág. 251, lín. 3, en cambio, el amanuense escribe «malditos errores». 
$\mathrm{Y}$, assí, vemos que por las piedras antiguas, que se hallaron en el Capitolio de Roma, se corrigen y enmiendan muchos herrores que los historiadores avían dexado escritos en sus historias ${ }^{57}$.

Aunque el dato más sobresaliente tiene lugar en el siguiente fragmento:

si se desprecia la authoridad de Dios, las jacciones appostólicas, los concilios universales $[\ldots]^{58}$.

En el texto, en donde figura tachada la palabra jacciones y escrita sobre ella traddiciones, lo ciertamente valioso es que jacciones, como en su caso ehtanpado, viene a probar de forma fidedigna la antigüedad de un fenómeno cuya realidad se ha venido relegando a un tiempo muy posterior. Al hilo del descubrimiento de estas inusitadas grafias, me pregunto qué valor se le hubiera atribuido a $h$ si en vez de jacciones se hubiera documentado hacciones, tal y como ocurre en los ejemplos citados a lo largo del trabajo. Evidentemente muy pocos hubieran aceptado que $h$ fuera una genuina manifestación de aspiración, como hasta el momento se le viene negando. La particularidad de hallar la palabra escrita con $j$ ha puesto, a mi parecer, las cosas en su justo término.

Pero aunque el testimonio incuestionable de la aspiración de $-s$ se haya adelantado casi en dos siglos, nadie puede sostener que un cambio de tal índole haya podido tener lugar a principios del siglo XVII. Por ello, si consideramos que el escribano en cuestión no fuera mayor de veinticinco años, tendríamos que anticipar el fenómeno hasta la segunda mitad del siglo XVI; pero como debió contraerlo en el ambiente familiar, si es que no estaba plenamente incrustado en el lenguaje de la sociedad granadina, según creo, habrá que estimar un origen aún más remoto, como conviene a un proceso de tamaña envergadura. En resumen, gran parte de la sociedad andaluza del XV, por ceñirnos exclusivamente a la región meridional en donde han aparecido los registros ehtanpado y jacciones, debió participar de dicho cambio fonológico.

Para corroborar lo anterior considero oportuno advertir que la sociedad canaria de 1501 no debió ser ajena al fenómeno, si nos atenemos al siguiente testimonio:

Alonso de las Hijas, asentado en la viga frontero de la iglesia dixo non me debes mi blason de mis harmas Hortega porque si me lo habeis de dar a de ser de todas tres leyes [...] ${ }^{59}$.

57 Ibidem, pág. 647, lín. 12.

58 Ibidem, pág. 403, lín. 7. El editor se hace eco de tal sustitución advirtiéndolo en la nota correspondiente.

${ }^{59} \mathrm{M}^{\mathrm{a}}$ Régulo Rodríguez, «Los judíos en la sociedad canaria del siglo XVI», Homenaje a David Gonzalo Maeso en su 75 aniversario, Universidad de Granada, 1977, págs 399-410, especialmente pág. 404 , nota 3 . 


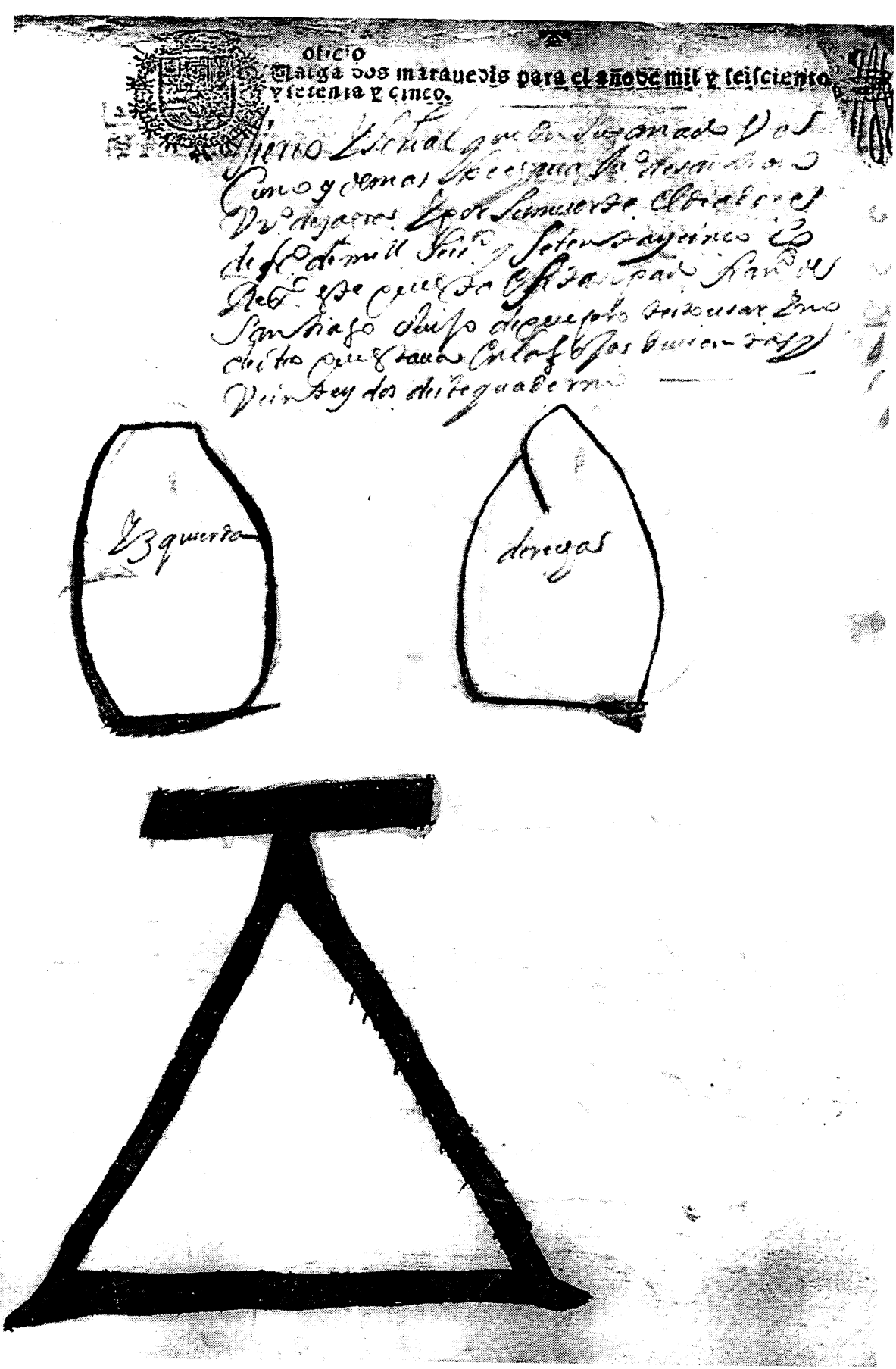

Texto n. ${ }^{\circ}$ 1: Corrección de ehtanpado 'estampado'. 


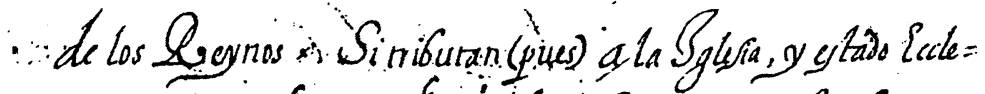

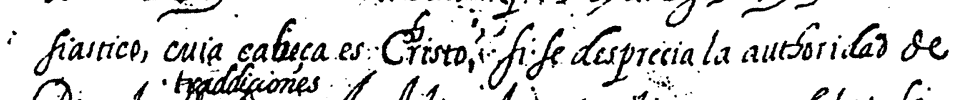

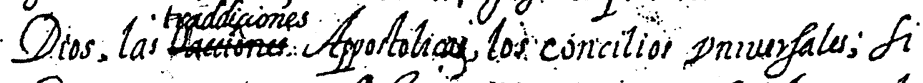

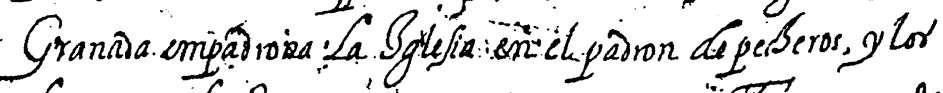

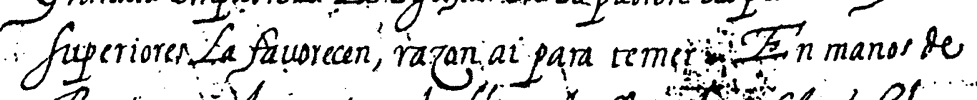

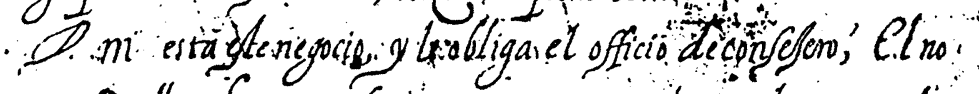

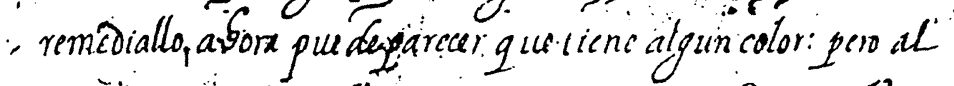
- movir aiotras youfficiones, y orrafiencia. Siruafe DM.

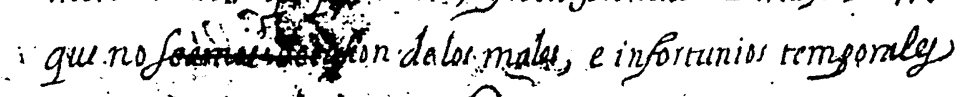

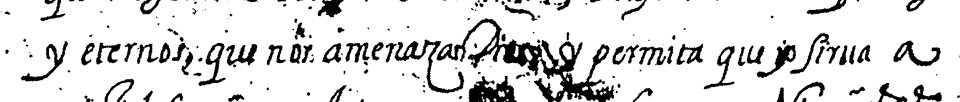

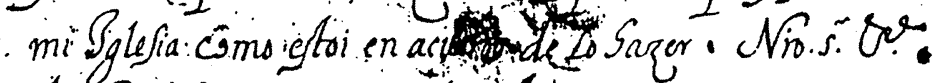

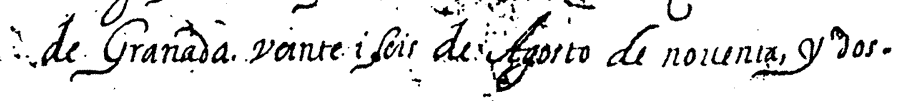

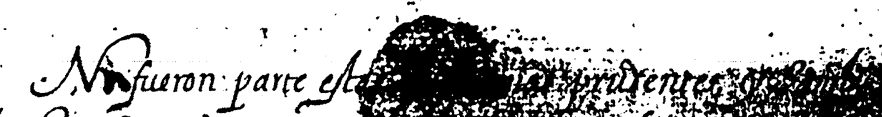

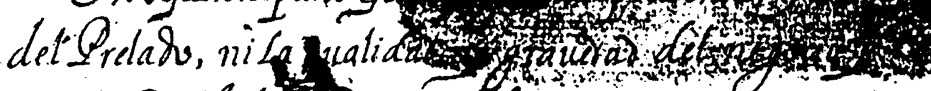

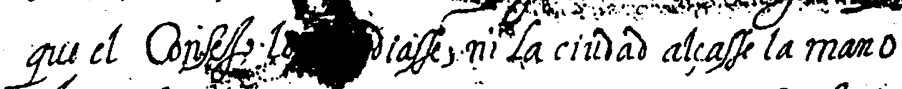

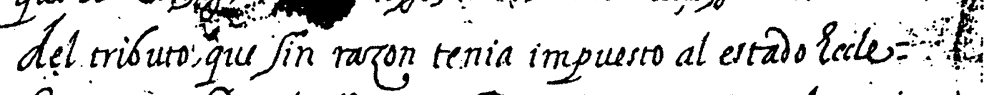
fiartico" Divulgaffe por la ciumbar lo que pasfance, las penas, y cenfuras engru aulian. incumbo Cor vetnicicuatos, frifficis; y. Regimiento, como no Lesporian abjoluer los confefores,

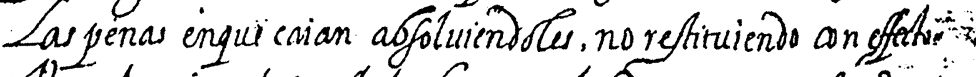

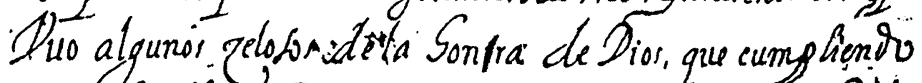

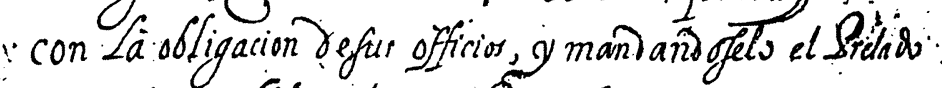

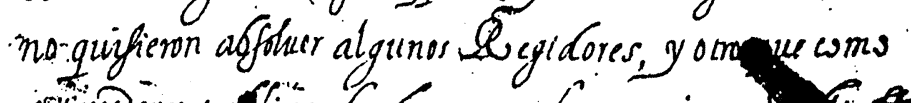

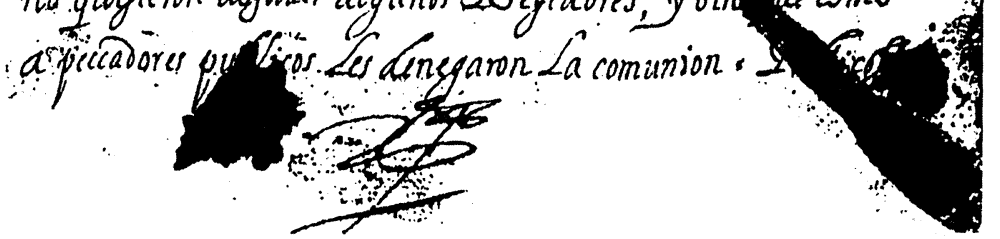
Texto n. ${ }^{\circ}$ 2: Tachadura y sustitución de jacciones 'acciones'. 
Los reiterados datos acopiados a lo largo del trabajo me hacen admitir que bajo la expresión «ni lo muy andaluz es auido por lenguaje esmerado» del aragonés Gonzalo García de Santa María subyace la existencia de un conjunto de rasgos fónicos espurios al sistema fonológico del castellano medieval, entre los que sin duda se encontraba el de la aspiración de $s$ final de sílaba y de palabra. 